\title{
CIAO: the CNR-IMAA advanced observatory for atmospheric research
}

\author{
F. Madonna, A. Amodeo, A. Boselli, C. Cornacchia, V. Cuomo, G. D’Amico, A. Giunta, L. Mona, and G. Pappalardo \\ Consiglio Nazionale delle Ricerche - Istituto di Metodologie per l'Analisi Ambientale CNR-IMAA, C. da S. Loja, Tito Scalo, \\ Potenza, 85050, Italy
}

Received: 27 July 2010 - Published in Atmos. Meas. Tech. Discuss.: 18 November 2010

Revised: 20 May 2011 - Accepted: 7 June 2011 - Published: 24 June 2011

\begin{abstract}
Long-term observations of aerosol and clouds are of crucial importance to understand the weather climate system. At the Istituto di Metodologie per l'Analisi Ambientale of the Italian National Research Council (CNR-IMAA) an advanced atmospheric observatory, named CIAO, is operative. CIAO (CNR-IMAA Atmospheric Observatory) main scientific objective is the long term measurement for the climatology of aerosol and cloud properties. Its equipment addresses the state-of-the-art for the ground-based remote sensing of aerosol, water vapour and clouds including active and passive sensors, like lidars, ceilometers, radiometers, and a radar. This paper describes the CIAO infrastructure, its scientific activities as well as the observation strategy. The observation strategy is mainly organized in order to provide quality assured measurements for satellite validation and model evaluation and to fully exploit the synergy and integration of the active and passive sensors for the improvement of atmospheric profiling. Data quality is ensured both by the application of protocols and dedicated quality assurance programs mainly related to the projects and networks in which the infrastructure is involved. The paper also introduces examples of observations performed at CIAO and of the synergies and integration algorithms (using Raman lidar and microwave profiler data) developed and implemented at the observatory for the optimization and improvement of water vapour profiling. CIAO database represents an optimal basis to study the synergy between different sensors and to investigate aerosolclouds interactions, and can give a significant contribution to the validation programs of the incoming new generation satellite missions.
\end{abstract}

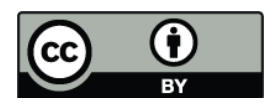

Correspondence to: F. Madonna (madonna@imaa.cnr.it)

\section{Introduction}

Aerosol, water vapour, and clouds as well as their reciprocal interactions play a crucial role as drivers of weather and climate system. Difficulties over their representation with sufficient accuracy within numerical models are responsible for most of the uncertainty of future global change and therefore there is a strong need for evaluating model capabilities to reproduce the behaviour of these key atmospheric parameters. The need for such observations has been also unambiguously asserted in the latest IPCC Fourth Assessment Report (IPCC, 2007), where it is remarked the primary importance of the knowledge of both the vertical dimension and the regional variability of atmospheric processes. As a consequence, the IPCC recommendations can be only fulfilled by performing long term observations that must be range resolved, with high spatial and temporal resolution.

A complete evaluation of model performances also requires the availability of long term ground based measurements of all relevant atmospheric parameters. Satellite observations need ground-based measurements for calibration and validation (GCOS, 2006). Space-based observations present the advantage of providing global spatial coverage, but they do not allow alone to study many atmospheric processes because of their not sufficient temporal coverage. This mainly concerns the polar-orbiting satellites, whose revisit time is still an important issue to be investigated in order to understand the representativeness of these satellite observations (Pappalardo et al., 2010). Ground-based observations are also necessary for the long-term monitoring of atmospheric parameters that cannot be observed from available satelliteborne sensors.

The importance of long-term observations of aerosol and clouds is related not only to the evaluation and the improvement of model parameterization but also to the integration of models and observations using suitable assimilation schemes. In the last few years, modellers, that traditionally

Published by Copernicus Publications on behalf of the European Geosciences Union. 
use standards measurements, like radiosoundings profiles, surface or columnar parameters for constraining model forecasts and analysis, are progressively increasing the number and the type of routine and systematic ground based observations that are assimilated in their numerical prediction models.

The detailed knowledge of optical, microphysical and radiative properties of aerosol and clouds is essential to understand their role in atmospheric processes, as well as their impact on human health and environment. Despite the considerable improvements made in the observation capability for aerosol and clouds characterization in the last decade, our knowledge is still limited.

To fill the existing gaps, the international scientific community is promoting the establishment of integrated global observing systems including ground-based, airborne in-situ measurements and space-borne observations in combination with advanced modelling. GEOSS architecture integrates environmental observations, monitoring data and measurements with modelling to support and inform environmental decision-makers (http://www.epa.gov/geoss/). This strategy is based on the necessity for sustainable long-term ground based observations (WMO, 2005).

In this scenario, existing ground based atmospheric advanced observatories, like for example those established in the frame of the ARM program in US (Stokes and Schwartz, 1994 - http://www.arm.gov), or CESAR at Cabauw in the Netherlands (Russchenberg et al., 2005 - http://www. cesar-observatory.nl) play an important role. These ground based anchor stations are equipped with state-of-art techniques and instruments and they are able to provide traceable observations and advanced/integrated products for climate and weather studies. In particular, these advanced products with high time-space resolution and high accuracy are strongly needed for the validation of new generation satellite missions, based on multi-purpose platforms equipped with different active and passive sensors.

CIAO, the CNR-IMAA Atmospheric Observatory, located in Southern Italy, operates in this scientific context in synergy with most of the European atmospheric observatories. In this paper, a description of the CIAO infrastructure and of its scientific objectives is given. The experimental field, the expertise and the observing strategy are presented in Sect. 2. In Sect. 3, the database, products and integration strategy are briefly described. In Sect. 4, examples of the observations performed and of synergy and integration techniques developed and implemented at the observatory is shown. Since it is difficult to provide a comprehensive example of all the activities ongoing at CIAO in one paper, we will focus on water vapour measurements.

\section{The CNR-IMAA Atmospheric Observatory (CIAO)}

CIAO is one of the most advanced infrastructures for ground based remote sensing in Europe. It is located in Tito Scalo, Potenza, Southern Italy, on the Apennine mountains $\left(40.60^{\circ} \mathrm{N}, 15.72^{\circ} \mathrm{E}, 760 \mathrm{~m}\right.$ a.s.l.), less than $150 \mathrm{~km}$ from the West, South and East coasts (Fig. 1). The site is in a plain surrounded by low mountains $(<1100 \mathrm{~m}$ a.s.l.). The observatory operates in a typical mountain weather strongly influenced by Mediterranean atmospheric circulation, resulting in generally dry, hot summers and cold winters. In this location, phenomena like orographically-induced effects on cloud formation can be studied. The site is particularly interesting for studying aerosol properties because it is affected by a quite large number of Saharan dust intrusions per year (Mona et al., 2006) and it is located $300 \mathrm{~km}$ far from the Etna Volcano (Pappalardo et al., 2004a). Moreover, the availability of simultaneous measurements of aerosol and cloud properties makes the site optimal also for the investigation of aerosolcloud interactions.

CIAO is run by the Istituto di Metodologie per l'Analisi Ambientale (IMAA) of the Italian National Research Council (CNR). At present, the observatory performs systematic aerosol measurements in the frame of EARLINET (European Aerosol Research LIdar NETwork) (http://www. earlinet.org) and continuous aerosol measurements in the frame of AERONET (AErosol RObotic NETwork) (http:// aeronet.gsfc.nasa.org). The CIAO infrastructure hosted international satellite validation experiments for the study of water vapour (e.g. EAQUATE - Taylor et al., 2008), it has been involved in several international experiments for the study of clouds and their modelling, and strongly cooperates with the Cloudnet (www.cloud-net.org). Moreover, since December 2009, CIAO is among the fifteen backbone stations involved in the operations of GRUAN (GCOS Upper-Air Reference Network - www.gruan.org).

At CIAO large attention has been traditionally paid to the study of aerosol and water vapour using lidar techniques (Pappalardo et al., 2004a, b, 2010; Mona et al., 2006, 2007, 2009). However, since 2004 the facility strengthened its observing capability for the monitoring of clouds through the acquisition of new active and passive microwave profilers, with the main objective to investigate aerosol-clouds interactions using both active and passive remote sensing techniques. The wide range of measurements provided at the facility makes it an ideal site for calibration, validation and intercomparison campaigns.

All the observations performed at CIAO are designed in order to be redundant, traceable and to follow the main international standards, provided by the WMO and other research programmes. 


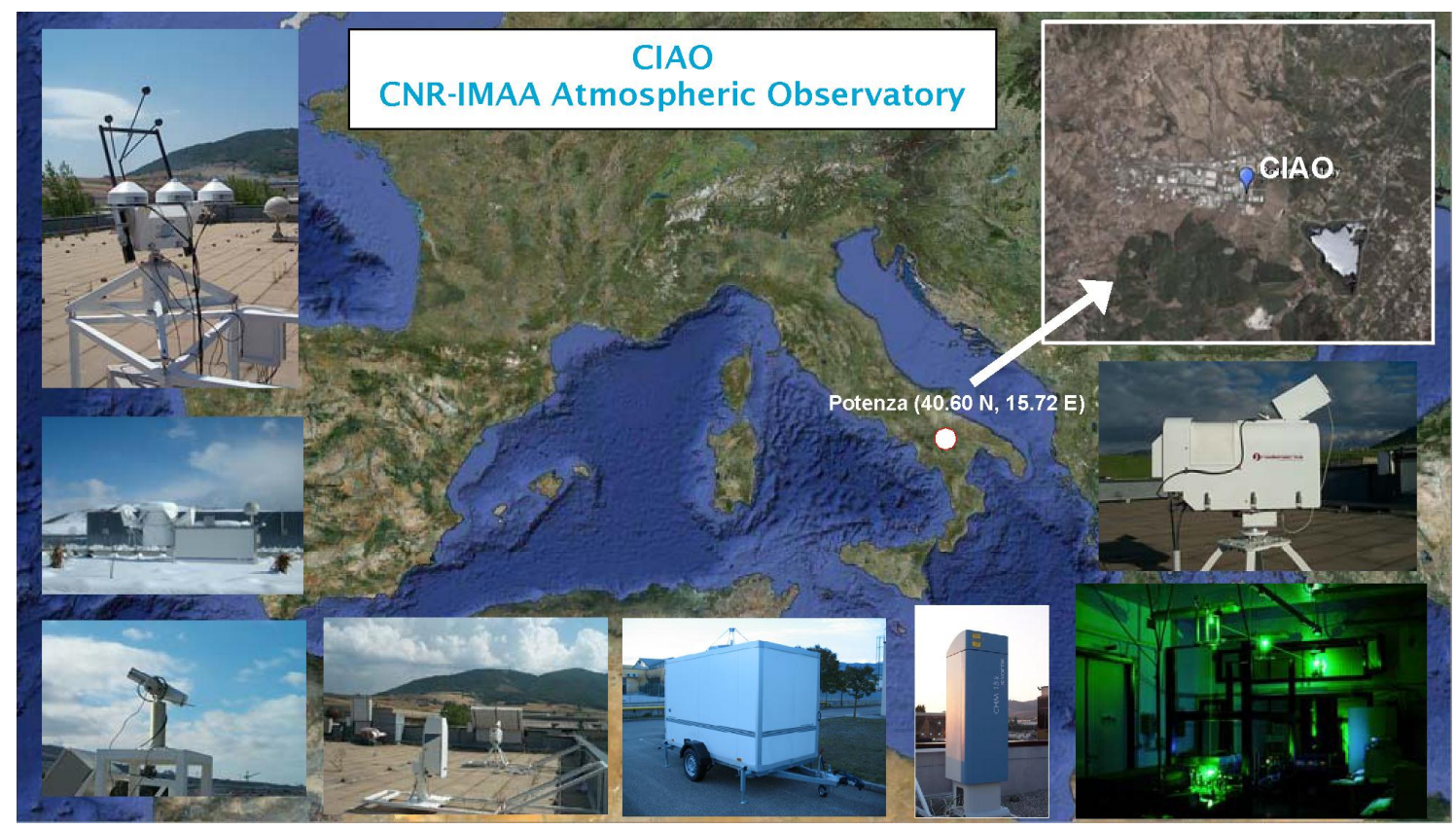

Fig. 1. Location of CIAO (CNR-IMAA Atmospheric Observatory) respect to the Mediterranean Basin and pictures of several active and passive instruments operative at the observatory.

The main research lines currently active at CIAO include:

a) design and implementation of lidar systems for aerosol, water vapour and cloud measurements;

b) development of algorithms for the integration of lidar and microwave radiometer measurements;

c) definition of measurements protocols, quality assurance programs and data managing strategies;

d) definition of suitable strategy for the satellite CAL/VAL;

e) analysis of the physical and dynamical processes related to aerosol transport, their modification and classification;

f) analysis and physical interpretation of observations provided by both active and passive sensors for the study of aerosol and clouds interactions and nucleation processes;

g) organization and participation in measurement campaigns;

h) development of methods for the evaluation of aerosol transport and of mesoscale weather prediction models;

i) networking.
So far, CIAO is also strongly operating in order to provide quality-controlled vertical profiles of clouds, humidity, temperature and aerosols. The quality assurance has been established mainly according to the EARLINET measurement protocol that aims at the establishment of a long-term statistically significant database of aerosol measurements for climatologic studies (Matthias et al., 2004). Data quality also matches the protocols developed in the frame of the international networks in which the other active and passive instruments are operational.

Another key issue related to the data quality is represented by the instrument intercomparison: this concerns both the comparison among different techniques measuring the same atmospheric key variables, routinely performed at CIAO for obtaining redundancy analysis, and the comparison among instruments of the same type, such as the EARLINET lidar intercomparison campaigns (SLiCE2000 and EARLI-09, Matthias et al., 2004 and Freudenthaler et al., 2010) or the radiometer intercomparison during the preparation phase of LAUNCH-2005 (Madonna et al., 2006).

The intensive exchange of expertise within EARLINET and with the main European atmospheric observatories (e.g. Cabauw, Chilbolton, Lindenberg, Payerne, Sodankyla) as well as the participation in GAW-GALION (Global Atmospheric Watch - Aerosol LIdar Observation Network - WMO report, 2008 ) and the contribution to the WMO Sand and Dust Storm Warning System (SDSWS, http://www.wmo.int/pages/prog/arep/wwrp/new/documents/ SDS_WAS_draft_implementation_plan.pdf), in the frame of 
the World Weather research programme, ensure a strong link with international programmes and organizations and, therefore, the development of CIAO research activities in agreement with the main international standards.

Finally, CIAO offers support to the activities of the local government, decision-makers, environmental agencies and the Italian Protection Agency.

In the following paragraphs, the CIAO equipment for ground-based observations of the atmosphere is described.

\subsection{Lidars}

Since 1993, lidar remote sensing of the atmosphere is one of the main research activities carried out at CNR-IMAA. Currently, three lidar systems are operative at CIAO, devoted to the study of aerosol, water vapour and clouds. All these lidar systems are designed and implemented within the Institute.

The multi-wavelength lidar system for tropospheric aerosol characterization, PEARL (Potenza EArlinet Raman Lidar), operative at CNR-IMAA since August 2005 (Mona et al., 2006, 2009) has been designed to provide simultaneous multi-wavelength aerosol measurements for the retrieval of optical and microphysical properties of the atmospheric particles (Ackermann et al., 1998; Müller et al., 2001) and water vapour mixing ratio profiles. This system is the result of the upgrade of a preexisting lidar system, operative since May 2000 in the frame of EARLINET - (Bösenberg et al., 2001). The system is based on a $50 \mathrm{~Hz} \mathrm{Nd:YAG}$ laser source emitting at $1064 \mathrm{~nm}$ and equipped with second and third harmonic generators. An optical system based on mirrors, dichroic mirrors and $2 \mathrm{X}$ beam expanders, separates the three wavelengths allowing to optimize the energy and the divergence for each wavelength. The beams are mixed again in order to get the collinearity of the three wavelengths and to transmit them simultaneously and coaxially with respect to the lidar receiver. The backscattered radiation from the atmosphere is collected by a F/10 Cassegrain telescope $(0.5 \mathrm{~m}$ diameter, $5 \mathrm{~m}$ focal length) and forwarded to the receiving system, equipped with 16 optical channels. Three channels are devoted to the detection of the radiation elastically backscattered from the atmosphere at the three laser wavelengths $(355 \mathrm{~nm}, 532 \mathrm{~nm}$ and $1064 \mathrm{~nm})$; three channels for the Raman radiation backscattered from the atmospheric $\mathrm{N}_{2}$ molecules at $387 \mathrm{~nm}$ and $607 \mathrm{~nm}$ and $\mathrm{H}_{2} \mathrm{O}$ molecules at $407 \mathrm{~nm}$. Two further channels detect the polarized components of the $532 \mathrm{~nm}$ backscattered light (perpendicular and parallel respect to the direction of the linearly polarized beam transmitted by the laser at $532 \mathrm{~nm}$ ). Each of these channels is further split into two channels differently attenuated for the simultaneous detection of the radiation backscattered from the low and high altitude ranges in order to extend and optimize the dynamic range. The spectral selection of the collected radiation is performed by means of dichroic mirrors and interference filters. Interference filter bandwidths is $0.5 \mathrm{~nm}$ at all the wavelengths for both night-time and day- time operations. For the elastic backscattered radiation at $1064 \mathrm{~nm}$ the detection is performed by using an APD detector and the acquisition is performed in analog mode. For all the other acquisition channels, the detection is performed by means of photomultipliers and the acquisition is in photoncounting mode. PEARL performs systematic measurements three times per week in the frame of EARLINET (Pappalardo et al., 2010), and during international experiments or special atmospheric events (saharan dust outbreaks, volcanic eruptions, etc.). The vertical resolution of the raw profiles is $7.5 \mathrm{~m}$ for $1064 \mathrm{~nm}$ and $15 \mathrm{~m}$ for the other wavelengths, whereas the temporal resolution is $1 \mathrm{~min}$.

MUSA (Multiwavelength System for Aerosol) is a mobile multi-wavelength lidar system based on a Nd:YAG laser equipped with second and third harmonic generators and on a $F / 3$ Cassegrain telescope with a primary mirror of $30 \mathrm{~cm}$ diameter and a focal length of $95 \mathrm{~cm}$. The three laser beams at 1064, 532 and $355 \mathrm{~nm}$ are simultaneously and coaxially transmitted into the atmosphere in bistatic configuration. The receiving system has 3 channels for the detection of the radiation elastically backscattered from the atmosphere and 2 channels for the detection of the Raman radiation backscattered by the atmospheric N2 molecules at 607 and $387 \mathrm{~nm}$. The elastic channel at $532 \mathrm{~nm}$ is split into parallel and perpendicular polarization components by means of a polarizer beamsplitter cube. The backscattered radiation at all the wavelengths is acquired both in analog and photon counting mode. The typical vertical resolution of the raw profiles is $3.75 \mathrm{~m}$ with a temporal resolution of $1 \mathrm{~min}$. The system is compact and transportable. It has been developed in cooperation with the Meteorological Institute of the LudwigMaximilians-Universität of Munich and it is one of the reference systems used in the frame of the EARLINET Quality Assurance program.

Both MUSA and PEARL allow independent measurements of the aerosol extinction and backscatter coefficients, and therefore of the lidar ratio at $532 \mathrm{~nm}$ and $355 \mathrm{~nm}$ (Ansmann et al., 1990; Pappalardo et al., 2004b). An iterative approach (Di Girolamo et al., 1995) is used for retrieving the aerosol backscatter coefficient at $1064 \mathrm{~nm}$ from the elastically backscattered lidar signal only. Therefore, MUSA and PEARL allow for a point-to-point comparison of the retrieved aerosol parameters. Moreover, both MUSA and PEARL are designed for depolarization measurements. Aerosol linear depolarization ratio measurements are obtained accordingly to Freudenthaler et al., 2009: in particular, the calibration of depolarization channels is made automatically using the " $+45^{\circ}$ method" for MUSA, while for PEARL the traditional " 0 " method" is used. The use of different calibration methods is due to the different receiver design for the depolarized radiation detection. MUSA has the capability to provide a high accurate calibration of aerosol depolarization thanks to its the presence of a linear polarized waveplate installed on motorized rotation mount. In the visible, PEARL collects not only the total backscattered radiation, 
but, at the same time, the parallel and perpendicular components of the depolarized radiation. According to the results reported in the peer-reviewed literature, this allows us to provide high accurate calibrated measurements of the depolarization ratio in the upper troposphere. An assessment of the calibration performance in the lower troposphere at CIAO is also planned. However, the complementarity of the two aerosol lidar systems is again clear in terms of redundant calibrated measurements of depolarization. Another key issue for redundancy is the fact that PEARL is a fixed systems and MUSA is mobile. This allows CIAO to participate in measurements campaign without creating significant gaps in the long term database.

In addition to MUSA and PEARL, CIAO is also equipped with a UV Raman lidar system for water vapour measurements (Mona et al., 2007), operational at CNR-IMAA since July 2002. It performs measurements simultaneously with PEARL. This system is based on a Nd:YAG laser with a repetition rate up to $100 \mathrm{~Hz}$ and typically operating at $50 \mathrm{~Hz}$. Radiation at $355 \mathrm{~nm}$ is transmitted into the atmosphere coaxially with respect to a F/10 Cassegrain telescope used as a receiver. The telescope is of the same type as PEARL. The backscattered radiation is selected by means of dichroic mirrors and interference filters and then is split into three channels, corresponding to the elastic backscattered radiation at $355 \mathrm{~nm}$, the $\mathrm{N}_{2}$ Raman shifted signal at $386.7 \mathrm{~nm}$ and the water vapour Raman shifted signal at $407 \mathrm{~nm}$. Interference filter bandwidths are kept below $1.0 \mathrm{~nm}$ and $0.3 \mathrm{~nm}$ for nighttime and daytime operations respectively, thus reducing the solar background during daytime measurements and limiting the effects of both atmospheric temperature variations on the measured signals (Behrendt and Nakamura, 2002) and interferences from liquid water Raman scattering (Whiteman et al., 2001). As for PEARL, the spectrally selected radiation is then split for each wavelength into two channels in order to preserve the linearity of the lidar signals over all altitude ranges. Photomultiplier tubes are used as detectors and both low and high range signals are acquired in photon counting mode. The typical vertical resolution of the raw profiles is $15 \mathrm{~m}$ with a temporal resolution of $1 \mathrm{~min}$.

The water vapour Raman lidar provides measurements of the water vapour mixing ratio profile as well as independent measurements of the aerosol extinction and backscatter coefficients at $355 \mathrm{~nm}$. Therefore, the presence of two lidar systems able to provide water vapour measurements (PEARL and the dedicated water vapour Raman lidar) enables a direct comparison of co-located mixing ratio profiles.

All these aspects crucially contribute to make CIAO strategy in line with the principles of complementarity and redundancy for both aerosol and water vapour measurements (Immler et al., 2010).

\subsection{Microwave profiler}

A ground-based microwave profiler (MP3014), designed by Radiometrics Corporation (Ware et al., 2003), is operational at CIAO since February 2004. It measures the sky brightness temperature $(\mathrm{Tb})$ at 12 frequencies: 5 in the K-band, distributed from the centre onto the wing of the $22 \mathrm{GHz}$ water vapour resonance absorption line, the rest are in the Vband, distributed on one shoulder of the $60 \mathrm{GHz}$ oxygen spinrotation band. The radiometer is equipped with an infrared thermometer (IRT), installed on the top of radiometer cabinet, able to measure zenith sky brightness temperature $(\mathrm{Tb})$ within the spectral range of 9.6 to $11.5 \mu \mathrm{m}$, and with surface meteorological sensors, used as constraints in the retrieval algorithm. The microwave profiler is also able to perform a 3-D scanning of the atmosphere though the measurements showed in the following are referred to $\mathrm{Tb}$ values obtained viewing only the zenith direction. The microwave profiler is also equipped with a rain effect mitigation system able to minimize error resulting from the accumulation of liquid water and ice on the microwave radiometer radome.

The $\mathrm{Tb}$ inversion provides temperature, humidity and cloud liquid water profiles up to $10 \mathrm{~km}$ above the ground station. Additionally, the inversion provides an estimation of the Integrated Precipitable Water Vapour (IPWV) and of the cloud Liquid Water Path (LWP). The uncertainty of the IPWV and LWP are calculated according to Cadeddu et al. (2009). The sky brightness temperatures are inverted using a neural network algorithm (Solheim et al., 1998) trained on about 10000 radiosounding profiles. Vertical profiles are output in $100 \mathrm{~m}$ up to $1 \mathrm{~km}$ and $250 \mathrm{~m}$ from 1 to $10 \mathrm{~km}$, with a minimum temporal resolution of $12 \mathrm{~s}$.

\subsection{Ka-band Doppler radar}

In March 2009, a meteorological Ka-Band cloud radar (MIRA36), designed by METEK GmbH, was installed at CIAO. It is a mono static magnetron-based pulsed Ka-Band Doppler radar for unattended long term observation of clouds properties. In the configuration operative at CIAO, linear polarized signal is transmitted while co- and cross polarized signals are received simultaneously to detect Doppler spectra of the reflectivity and Linear Depolarization Ratio (LDR). The reflectivity is used to determine the density of cloud constituents while LDR helps to identify the target type. The radar has a $1 \mathrm{~m}$ diameter antenna and emits the microwave radiation at $35.5 \mathrm{GHz}$ with a peak power of $30 \mathrm{~kW}$, a pulse width of $200 \mathrm{~ns}$ and a pulse repetition rate of $5 \mathrm{KHz}$. The antenna beam width is $0.6^{\circ} \times 0.6^{\circ}$ (gain $49 \mathrm{dBi}$ ) and the radar sensitivity is $-40.3 \mathrm{dBZ}$ at $5 \mathrm{~km}$ ( $0.1 \mathrm{sec}$ time resolution) while the Doppler velocity resolution is $0.02 \mathrm{~m} \mathrm{~s}^{-1}$. The receiver calibration is within an accuracy of less than $+/-1 \mathrm{~dB}$. This system is able to provide high accurate measurements of the reflectivity factor with a vertical resolution up to $15 \mathrm{~m}$, though the current configuration is set to a vertical resolution 
of $30 \mathrm{~m}$. The system is equipped with a clutter fence that strongly suppresses the ground clutter echo. The radar is also equipped with a 3-D scanning unit and it has been the first radar system in Europe working in Ka-band with the possibility of performing $\mathrm{a} \pm 90^{\circ}$ scanning of the atmosphere.

\subsection{Ceilometers}

Among the active remote sensing devices, two laser ceilometers are also operational at CIAO. Since August 2004, a CT25K ceilometer type, manufactured by VAISALA, continuously measures the cloud-base height and the signal backscattered by atmospheric particles. The ceilometer is basically an elastic backscatter lidar system that employs a pulsed In-Ga-As diode laser emitting at $905 \mathrm{~nm}$ wavelenght using a high repetition rate $(1.6 \mu \mathrm{J}$ of energy per pulse at $6.67 \mathrm{kHz}$ ) and detects the elastic backscattered radiation. Depending on the cloud optical thickness, CT25K processing software, designed by VAISALA, is able to provide up to three cloud layer heights simultaneously. Besides cloud layers, it also provides the profile of an uncalibrated backscattering coefficient at $905 \mathrm{~nm}$ up to $7.5 \mathrm{~km}$ with a vertical resolution of $30 \mathrm{~m}$ and a temporal resolution of $15 \mathrm{~s}$.

Since September 2009, a second ceilometer for cloud base measurements, CHM15k type manufactured by Jenoptik Laser Optik Systeme, is operative at CIAO. It is able to measure the cloud base height of cloud layers up to $15 \mathrm{~km}$ above the ground with the possibility to investigate the optical properties of cirrus clouds up to the tropopause. CHM15k employs a Nd:YAG pumped diode laser emitting at $1064 \mathrm{~nm}$ wavelenght using a high repetition rate $(8 \mu \mathrm{J}$ of energy per pulse at $5.58 \mathrm{kHz}$ ) and it is equipped with a photon counting acquisition system. As for the CT25K ceilometer, CHM15k processing software, designed by Jenoptik, provides up to three cloud layer heights simultaneously, but it also provides the retrieval of the boundary layer height and of the cloud penetration depth. The $1064 \mathrm{~nm}$ raw signal has a vertical resolution of $15 \mathrm{~m}$ and a temporal resolution of $30 \mathrm{~s}$.

\subsection{Other passive systems}

CIAO is also equipped with a CIMEL CE-318 sun photometer for measuring atmospheric aerosol columnar properties. This is a multi-channel, automatic sun-and-sky scanning radiometer that measures the direct solar irradiance and sky radiance at the Earth's surface. It is operative within AERONET and it provides the aerosol optical depth (AOD) at $340,380,440,500,675,870,1020$ and $1640 \mathrm{~nm}$ (Holben et al., 2001), along with the water vapour column content and the estimation of several optical and microphysical aerosol properties, such as the refractive index and the size distribution. The system is fully automatic and powered using solar panels. The measured radiances are automatically sent to the NASA-GSFC where they are processed according to the AERONET data analysis. A cloud mask is also applied to remove cloud contamination. The system is calibrated on average once per year and after the calibration procedure quality assured data are released on the AERONET website. Since June 2010, CIAO sun photometer is also running using the new AERONET "cloud mode" capability with the aim to improve cloud optical depth observations (Chiu et al., 2010).

CIAO interest in sun photometer measurements is also related to the synergy with aerosol lidar measurements. Actually, the combination of multi-wavelength lidar profiling measurements with the columnar aerosol optical depths provided by the sun photometer allows us to improve the accuracy of the retrieval of aerosol microphysical properties (Müller et al., 2006).

CIAO also operates an automatic station equipped with high class broad band radiometers. A solar tracker automatically manages the position of the operating sensors in compliance with the sun position. The station includes a two shaded pyranometers $(0.2-3.6 \mu \mathrm{m})$ and a shaded pyrgeometer $(4.5-42 \mu \mathrm{m})$ deployed for measuring the downwelling diffuse solar radiation scattered by the atmosphere and the downwelling infrared radiation incident at the surface, respectively. Furthermore, a pyrheliometer measures direct or un-scattered solar radiation $(0.2-4.0 \mu \mathrm{m})$. The measured solar and longwave irradiances can be suitably processed to retrieve the shortwave and longwave clear sky fluxes.

A Trimble GPS antenna/receiver station is operative and CIAO is going to be part of the NOAA GPS network by the end of 2011. As soon as the station will be formally included in the NOAA network, the NOAA GPS products from CIAO station, including the integrated water vapour estimation, will be available to the users in near real-time.

\subsection{In-situ measurements}

Balloon-based observations of temperature, pressure, humidity and winds are performed at CIAO using three different radiosounding systems: the VAISALA AS13 autosonde system and two manual VAISALA radiosouding systems (MW21 and PP15). The automatic radiosounding station is able to perform up to 24 radiosoundings automatically and remotely controlled. Moreover, the system is also scheduled for activating up to two spare radiosoundings in order to prevent from any faults in the launch procedure. GPS height on balloons is also available for the AS13 and MW21 systems allowing for the retrieval of the vertical profile of wind direction and speed. MW21 is also able to manage the data received from the ozonesonde digital interface for measurements of the ozone mixing ratio vertical profile up to about $40 \mathrm{~km}$ a.g.l. All the systems are periodically upgraded and recalibrated by the manufacturer.

CIAO radiosouding database consists of routine launches performed simultaneously to the water vapour Raman lidar systematic night time measurements and of intensive radiosouding samplings (up to 5-6 launches per day) 
carried out in the frame of international measurements campaigns. Radiosounding launches are currently performed using RS92-SGP, whereas, in the past, RS80 and RS90 sondes have been used. Comparison of different radiosonde types have been performed both to assess possible biases in the collected database and to ensure a proper management of the device change. Examples of these comparisons are provided in Sect. 4.1.

Since the beginning of 2010, according to a preliminary protocol established in the frame of GRUAN, CIAO is performing one weekly RS92-SGP launch using the autosonde launcher. Moreover, it is going in the next future to perform a monthly stratospheric water vapour launch, simultaneously to the weekly autosonde launch, using the RDD-100 prototype sondes (http://www.vaisala.com/ en/products/soundingsystemsandradiosondes/radiosondes/

Pages/referenceradiosonde.aspx).

Standard surface variables (pressure, temperature, humidity and wind) are routinely monitored using the VAISALA MILOS520 Automatic Weather Station, with a typical temporal resolution of $1 \mathrm{~min}$. The station is also equipped with additional sensors for the measurements of present weather, visibility and rain gauge.

\section{Products, database and integration strategy}

Table 1 reports the list of all the instruments operative at CIAO. For each of them, the level 1 (lv1) and level 2 (lv2) products they provide and the retrieval algorithms currently in use for the lv2 data processing are included. According to the architecture of the CIAO database, level 0 data (lv0) are represented by the raw measurements output of each instrument (e.g. the number of photons collected by the lidar or the voltages measured by the microwave profiler). The lv1 products are referred to the "raw products", for example the lidar range-corrected signals or the microwave brightness temperatures. The lv2 products indicate the estimation of atmospheric parameters retrieved from the application of suitable algorithms to the lv1 products, like the water vapour mixing ratio measured by lidar and temperature profile measured by microwave. In Table 1, it is also reported the quality assurance program/protocol used for the provision of the final (quality assured) data to the CIAO database. Finally, the list of the advanced products obtained from the integration of the data provided by different instruments is reported.

The CIAO database is organized in order to collect both the raw data $(\operatorname{lv} 0,1 v 1)$ and the final quality assured products (lv2). All the data are archived in NetCDF format and each file contains all the necessary information for its use in evaluation/validation procedures as well as to reprocess the data in case of availability of new calibration or retrieval schemes. Before archiving, all the data also undergo the quality assurance protocols reported in Table 1.
The database is accessible through the CIAO website (www.imaa.cnr.it) behind a request to the instrument PI. Each instrument PI is also in charge of both checking the status of maintenance procedures and supporting the users. The database and most of the real-time quicklooks of the collected data are also accessible from the websites of the networks in which the CIAO is involved.

In order to fully exploit the simultaneous use of different ground based remote sensing techniques, a suitable integration strategy has been adopted at CIAO. The strategy is based on two main points: redundancy and complementarity. Redundancy is necessary to collect a large dataset of observations for comparisons, intercalibrations and cross checks of the retrieved parameters, also improving the measurement traceability; complementarity is important in order to overrun the intrinsic limits of each single observation technique, to reduce measurement uncertainty and to extend the sounding vertical range covering nearly all weather conditions. This strategy also includes the design and the implementation phases of the instruments and the elaboration of suitable retrieval algorithms for the integration of active and passive observations. The development of integration algorithms also enhances the capability of evaluating the performances of model outputs and satellite retrievals and of identifying possible discrepancies and spurious trends.

\section{Water vapour measurements}

In this section, a few examples of observations performed at CIAO and of the synergies and integration algorithms elaborated and currently in use is presented. The large number of instruments available and products released at the observatory makes difficult the provision of a comprehensive example of all the observations currently performed at the observatory. In the following, we will focus on the optimization and improvement of water vapour profiling using observations collected with radiosondes, Raman lidar and microwave profiler as well as on the integration of Raman lidar and microwave profiler measurements.

Water vapour and cloud measurements still represent a crucial issue in the atmospheric studies. Tropospheric water vapour and its content in clouds is a fundamental variable for understanding the physical processes occurring within clouds and the radiative forcing due to clouds and water vapour and their feedback processes are one of the main uncertainties towards an accurate evaluation of Earth's radiative budget (IPCC, 2007). Furthermore, satellite and model validation needs improved accuracy and long term database of measurements with high-resolution in time and space. Actually, modelling community clearly shows a strong interest in the water vapour profiling measurements because of its high variability that makes necessary a long-term comparison between accurate high resolution observations and the forecast/analysis of operational mesoscale models. The 
Table 1. (first part) List of the instruments operative at CIAO along with the corresponding lv1 and lv2 products, the retrieval algorithm currently in use for obtaining lv 2 products, the corresponding quality assurance protocol and the advanced products obtained from the synergy and integration of different techniques.

\begin{tabular}{|c|c|c|c|c|c|}
\hline Instrument & lv1 products & 1v2 products & Algorithm & $\begin{array}{l}\text { Quality assurance } \\
\text { protocol }\end{array}$ & $\begin{array}{l}\text { Advanced and Syner- } \\
\text { getic products }\end{array}$ \\
\hline $\begin{array}{l}\text { PEARL (Potenza } \\
\text { EArlinet Raman } \\
\text { Lidar) }\end{array}$ & $\begin{array}{l}\text { RCS at } 355,386,407, \\
532,532 \text { parallel, } 532 \\
\text { cross, } 607,1064 \mathrm{~nm}\end{array}$ & $\begin{array}{l}\beta \text { at } 355 / 532 / 1064, \\
\alpha \text { at } 355 / 532, \tau \text { at } \\
355 / 532, \chi \text { at } 355 / 532 \\
\text { and at } 532 / 1064, \delta \text { at } \\
532 \mathrm{~nm}\end{array}$ & $\begin{array}{l}\text { Ansmann } \\
\text { et al., } 1990 \\
\text { Pappalardo } \\
\text { et al., 2004b } \\
\text { Freudenthaler } \\
\text { et al., } 2009 \\
\text { Di Girolamo } \\
\text { et al., } 1995\end{array}$ & $\begin{array}{l}\text { EARLINET Quality } \\
\text { assurance programme }\end{array}$ & $\begin{array}{l}\text { Aerosol } \\
\text { Microphysical } \\
\text { properties } \\
\text { (Mueller } \\
\text { et al. 2009) }\end{array}$ \\
\hline $\begin{array}{l}\text { MUSA } \\
\text { (MUltiwavelength } \\
\text { System for Aerosol) } \\
\text { lidar }\end{array}$ & $\begin{array}{l}\text { RCS at } 355,386,407, \\
532,532 \text { parallel, } 532 \\
\text { cross, } 607,1064 \mathrm{~nm}\end{array}$ & $\begin{array}{l}\beta \text { at } 355 / 532 / 1064, \\
\alpha \text { at } 355 / 532, \tau \text { at } \\
355 / 532, \chi \text { at } 355 / 532 \\
\text { and at } 532 / 1064, \delta \text { at } \\
532 \mathrm{~nm}\end{array}$ & $\begin{array}{l}\text { Ansmann } \\
\text { et al., } 1990 \\
\text { Pappalardo } \\
\text { et al., 2004b } \\
\text { Freudenthaler } \\
\text { et al., } 2009 \\
\text { Di Girolamo } \\
\text { et al., } 1995\end{array}$ & $\begin{array}{l}\text { EARLINET Quality } \\
\text { assurance programme } \\
\text { EARLINET reference } \\
\text { mobile system }\end{array}$ & $\begin{array}{l}\text { Aerosol } \\
\text { Microphysical } \\
\text { properties } \\
\text { (Mueller } \\
\text { et al., 2009) }\end{array}$ \\
\hline $\begin{array}{l}\text { CIAO water vapour } \\
\text { Raman lidar }\end{array}$ & $\begin{array}{l}\mathrm{RCS} \text { at } 355,386,407 \\
\mathrm{~nm}\end{array}$ & $\begin{array}{l}\beta, \alpha, \tau \text { at } 355 \mathrm{~nm}, \\
\text { WVMR }\end{array}$ & $\begin{array}{l}\text { Raman retrieval } \\
\text { (Mona et al., 2007) }\end{array}$ & $\begin{array}{l}\text { Intercomparison } \\
\text { within Italian } \\
\text { NDACC stations }\end{array}$ & $\begin{array}{l}\text { Water vapour Raman } \\
\text { lidar + microwave } \\
\text { profiler for water } \\
\text { vapour retrieval using } \\
\text { Kalman filtering }\end{array}$ \\
\hline $\begin{array}{l}\text { MIRA-36 Ka-band } \\
\text { Doppler Polarimetric } \\
\text { radar }\end{array}$ & $\begin{array}{l}\text { SNR, Z, Ze, Doppler } \\
\text { velocity, LDR }\end{array}$ & $\begin{array}{l}\text { LWC, IWC, Target } \\
\text { classification }\end{array}$ & $\begin{array}{l}\text { Cloudnet Retrieval } \\
\text { Scheme (Illingworth } \\
\text { et al., 2007) }\end{array}$ & $\begin{array}{l}\text { Cloudnet quality } \\
\text { assurance }\end{array}$ & \multirow{2}{*}{$\begin{array}{l}\text { Radar reflectivity } \\
+ \text { microwave temperature } \\
\text { profile for melting layer } \\
\text { retrieval }\end{array}$} \\
\hline $\begin{array}{l}\text { MP3014 Microwave } \\
\text { Profiler }\end{array}$ & $\begin{array}{l}\text { K-band and V-band } \\
\text { Tbs }\end{array}$ & $\begin{array}{l}\text { Temperature, } \\
\text { WVMR, relative } \\
\text { humidity and liquid } \\
\text { water profiles, IPWV, } \\
\text { LWP }\end{array}$ & $\begin{array}{l}\text { Neural network algo- } \\
\text { rithm (Solheim } \\
\text { et al., 1998) }\end{array}$ & $\begin{array}{l}\text { Intercomparison with } \\
\text { radiosoundings and } \\
\text { water vapour Raman } \\
\text { lidar }\end{array}$ & \\
\hline $\begin{array}{l}\text { CIMEL CE-318 sun } \\
\text { photometer }\end{array}$ & $\begin{array}{l}\text { Radiances at } 330, \\
380,440,500,670, \\
880,1060,1640 \mathrm{~nm}\end{array}$ & $\begin{array}{l}\text { AOT, } \chi \text { at } 440 / 880, \\
\text { IPWV, Microphysical } \\
\text { properties }\end{array}$ & $\begin{array}{l}\text { AERONET } \\
\text { automatic retrieval } \\
\text { (aeronet.gsfc.nasa.gov) }\end{array}$ & $\begin{array}{l}\text { AERONET } 1 \mathrm{v} 2.0 \\
\text { quality assured data }\end{array}$ & $\begin{array}{l}\text { Multiwavelength lidar } \\
+ \text { sun photometer } \\
\text { for the retrieval of } \\
\text { aerosol microphysical } \\
\text { properties (to be } \\
\text { implemented, Mueller } \\
\text { et al. 2009) }\end{array}$ \\
\hline
\end{tabular}

$\alpha$ : Extinction coefficient; $\beta$ : Backscattering coefficient; $\delta$ : Depolarization ratio; $\tau$ : Optical depth; $\chi$ : Angström coefficient; AOT: Aerosol Optical Depth; IPWV: Integrated Precipitable Water Vapour; IWC: Ice Water Content; LDR: Linear Depolarization Ratio; LWC: Liquid Water Content; LWP: Liquid Water Path; RCS: Range-Corrected Signal; SNR: Signal-to-Noise Ratio; Tb: Brightness Temperature; WVMR: Water Vapour Mixing Ratio; Z: Reflectivity factor; Ze: Equivalent reflectivity factor; ZTD: Zenith Total Delay.

large dataset collected at CIAO is a good opportunity to perform a climatologic study of water vapour, in particular in the boundary layer where both aerosol and water vapour contents are higher and more variable, to study cloud formation and to evaluate the model capability both of capturing main structures of the water vapour field and of improving their parameterizations. In the next sub-section, examples of the water vapour measurements performed at CIAO using radiosoundings, Raman lidar and microwave profiler are provided. Two examples of the possible synergies and integrations between active and passive techniques are also described. These examples are also oriented to the optimization of water vapour ground-based profiling during cloudy conditions. In particular, it is described the procedure for the calibration of the water vapour mixing ratio profile obtained from the Raman lidar using the estimation of the IPWV retrieved by a microwave profiler. Moreover, an integration retrieval scheme for the profiling of water vapour through the integration of Raman lidar and microwave measurements, based on the use of the Kalman filter, is described and discussed. 
Table 1. (second part): List of the instruments operative at CIAO along with the corresponding lv1 and lv2 products, the retrieval algorithm currently in use for obtaining lv 2 products, the corresponding quality assurance protocol and the advanced products obtained from the synergy and integration of different techniques.

\begin{tabular}{|c|c|c|c|c|c|}
\hline Instrument & lv1 products & lv2 products & Algorithm & $\begin{array}{l}\text { Quality assurance } \\
\text { protocol }\end{array}$ & $\begin{array}{l}\text { Advanced and } \\
\text { Synergetic products }\end{array}$ \\
\hline $\begin{array}{l}\text { CT25K VAISALA } \\
\text { ceilometer }\end{array}$ & - & $\begin{array}{l}\text { Uncalibrated } \\
\text { backscattering profile, } \\
\text { visibility, cloud base } \\
\text { height }\end{array}$ & $\begin{array}{l}\text { Manufacturer } \\
\text { retrieval scheme }\end{array}$ & $\begin{array}{l}\text { Intercomparison with } \\
\text { lidars }\end{array}$ & $\begin{array}{l}\text { Microwave profiler } \\
\text { neural retrieval + } \\
\text { ceilometer (or lidar) } \\
\text { cloud base height for } \\
\text { LWP retrieval. }\end{array}$ \\
\hline $\begin{array}{l}\text { CHM15k Jenoptik } \\
\text { ceilometer }\end{array}$ & RCS 1064 nm & $\begin{array}{l}\text { Cloud base height, } \\
\text { PBL, visibility, } 1064 \\
\text { nm backscattering } \\
\text { profile }\end{array}$ & $\begin{array}{l}\text { Manufacturer } \\
\text { retrieval scheme }\end{array}$ & $\begin{array}{l}\text { Intercomparison with } \\
\text { lidars }\end{array}$ & \\
\hline $\begin{array}{l}\text { Surface radiation } \\
\text { station }\end{array}$ & $\begin{array}{l}\text { Surface downwelling } \\
\text { irradiances: solar } \\
\text { direct, diffuse, } \\
\text { global; longwave ra- } \\
\text { diation }\end{array}$ & $\begin{array}{l}\text { Shortwave and } \\
\text { longwave clear } \\
\text { sky fluxes }\end{array}$ & - & To be implemented & - \\
\hline Infrared thermometer & $\begin{array}{l}\mathrm{Tb} \text { in the } 9.6-11.8 \mu \mathrm{m} \\
\text { region }\end{array}$ & $\begin{array}{l}\text { Cloud base } \\
\text { temperature }\end{array}$ & $\begin{array}{l}\text { Manufacturer } \\
\text { retrieval scheme }\end{array}$ & $\begin{array}{l}\text { Intercomparison with } \\
\text { lidars and ceilometers }\end{array}$ & $\begin{array}{l}\text { Microwave } \\
\text { temperature profile } \\
+\mathrm{Tb} \text { in } 9.6-11.8 \mu \mathrm{m} \\
\text { band for cloud base } \\
\text { retrieval - }\end{array}$ \\
\hline $\begin{array}{l}\text { Automatic/Manual } \\
\text { radiosouding systems }\end{array}$ & - & $\begin{array}{l}\text { Temperature, } \\
\text { pressure, relative } \\
\text { humidity, wind profile } \\
\text { up to } 35 \mathrm{~km} \text { a.g.l. }\end{array}$ & - & GRUAN protocols & \\
\hline Ozonesounding & - & $\begin{array}{l}\text { Ozone mixing ratio } \\
\text { profile up to } \\
40 \mathrm{~km} \text { a.g.l. }\end{array}$ & - & GRUAN protocols & - \\
\hline $\begin{array}{l}\text { MILOS surface } \\
\text { meteorological } \\
\text { station }\end{array}$ & - & $\begin{array}{l}\text { Surface temperature, } \\
\text { pressure, relative } \\
\text { humidity and wind } \\
\text { direction/velocity, } \\
\text { rain gauge }\end{array}$ & - & GRUAN protocols & - \\
\hline GPS antenna/receiver & ZTD & IPWV & $\begin{array}{l}\text { NOAA GPS-Met } \\
\text { retrieval scheme }\end{array}$ & $\begin{array}{l}\text { In implementation } \\
\text { (End of 2011) }\end{array}$ & - \\
\hline
\end{tabular}

$\alpha$ : Extinction coefficient; $\beta$ : Backscattering coefficient; $\delta$ : Depolarization ratio; $\tau$ : Optical depth; $\chi$ : Angström coefficient; AOT: Aerosol Optical Depth; IPWV: Integrated Precipitable Water Vapour; IWC: Ice Water Content; LDR: Linear Depolarization Ratio; LWC: Liquid Water Content; LWP: Liquid Water Path; RCS: Range-Corrected Signal; SNR: Signal-to-Noise Ratio; Tb: Brightness Temperature; WVMR: Water Vapour Mixing Ratio; Z: Reflectivity factor; Ze: Equivalent reflectivity factor; ZTD: Zenith Total Delay.

\subsection{Radiosoundings}

Radiosounding launches are performed at CIAO with the purposes both to investigate the atmospheric parameters using in situ measurements and to provide reference measurements for the calibration of Raman lidar profiles (described in the following section).

As mentioned in Sect. 2.6, the availability of three radiosouding systems allows us to perform dual launches for intercomparing different radiosonde types and different receiving stations. CIAO archive contains either several example of dual sonde launches performed using the manual and the automatic launch systems or co-located and simulta- neous radiosoundings and remote sensing profiling measurements, in particular using the Raman lidar and the microwave profiler. This redundant dataset is the basis for performing redundant analysis in order to assess and reduce measurements uncertainties. In particular, studies for evaluating radiosounding representativeness, estimating its impact on the uncertainty of the measured parameters and addressing instrument co-location issues are in progress.

Several multiple balloon launches using different radiosonde types (RS80, RS90 and RS92) have been performed to assess and diagnose instrument failure and characterize instrument biases like the RS80 sonde dry-bias problem (Turner et al., 2003), taking also advantage of the 
availability of multiple stations. In Fig. 2, two examples of dual launches performed at CIAO are shown. In Fig. 2a and $\mathrm{b}$, temperature and humidity profiles collected using co-located and simultaneous RS92-SGP and RS92-KL sondes, launched using the manual procedure and the autosonde launcher, respectively, are compared. The distance between the two systems is about $50 \mathrm{~m}$ and the average start time difference between the two launches is within $10 \mathrm{~s}$. The example reported shows the typical good agreement between the temperature profiles with differences in the stratosphere due to small scale fluctuations of the temperature field (Lilly et al., 1974). The comparison between the RH profiles, instead, shows differences lower than $5 \%$ up to $14 \mathrm{~km}$ above the station, and less than $10 \%$ above. In both the considered regions, the differences are mainly due to the distance gained by the sondes during the flight and to the strong variability of water vapour field.

In Fig. 2c and d temperature and humidity profiles measured using RS80 and RS92-SGP sondes are compared. This comparison aimed at the evaluation the problems of RS80 sonde dry-bias (Turner et al., 2003). Plot in Fig. 2d also includes the RS80 humidity profile corrected for the drybias problem according to Leiterer method (Leiterer et al., 1997). An optimal agreement is observed between the temperature profiles. The comparison of the relative humidity profiles, instead, shows a significant difference between the RS92 and RS80 profile in the region located from 8.6 to $15.7 \mathrm{~km}$ a.g.l. and, at the same time, the good performance of Leiterer correction in reducing the dry-bias affecting RS80 in this region. The difference between the RS92 and RS80 $\mathrm{RH}$ profiles is reduced on average from less than $10 \%$ to less than $1 \%$ up to $12.5 \mathrm{~km}$ above the ground in the dry-bias region.

The database of dual launches flying different radiosounding types also ensures a consistent use of the data collected with different sensors providing essential information for the management of change of radiosounding type.

\subsection{Calibration of water vapour Raman lidar}

Raman lidar profiling is one of the most powerful techniques for the study of atmospheric water vapour distribution due to its capability to provide high resolution measurements both in space and time. Raman lidar profiling is a well established technique even if there are still some crucial issues that need to be better addressed, the main of which are related to the lidar system calibration (Sherlock et al., 1999; Whiteman et al., 2001), the overlap function (Wandinger and Ansmann, 2002; Whiteman et al., 2006), the temperature sensitivity of the Raman backscattering spectrum (Whiteman, 2003a), and the correction for the aerosol extinction contribution (Whiteman, 2003b).

Water vapour Raman lidar observations at CIAO are systematically evaluated considering all these different aspects. In this section the procedure for the calibration of the water vapour Raman profiles based on the IPWV retrieved using the microwave profiler is described.

So far, water vapour Raman lidar profiles are calibrated using either absolute or relative calibration methods. According to the comparisons reported in literature, higher performances are granted to the relative methods. The accuracy of a relative calibration method can stay within $5 \%$ while the accuracy of the absolute calibration is within $10 \%$ (Whiteman et al., 2001). The traditional strategy adopted at CIAO for the calibration of water vapour Raman lidar profiles is based on the determination of the calibration constant by the comparison with the simultaneous and co-located radiosounding profiles. The calibration constant of the Raman lidar system has been first determined during a calibration campaign (May-June 2002), resulting stable within $5 \%$, and re-evaluated after a system change in November 2008. About 200 radiosonde launches in May 2002-June 2006 period have been used for checking systematically the stability of the calibration constant. The uncertainty on the calibration constant using radiosondes is typically within $5 \%$ (Cornacchia et al., 2004; Mona et al., 2007).

Nevertheless, since 2004 IPWV microwave retrievals have been used for monitoring the stability of the calibration not only among measurements of different days, but also within each daily time series increasing the accuracy and physical consistency of the derived profiles as well as highlighting possible dependences on the stability of the lidar system. The application of this approach is limited to night time measurements, even though a qualitative comparison can be also operated during daytime.

In order to use the IPWV microwave retrieval for calibration purposes, some assumptions are necessary since the lidar profiles cover nearly the full troposphere but not the entire investigated atmospheric column. These assumptions are related to the system overlap function problems and to the signal-to-noise of the lidar signals in the upper troposphere/lower stratosphere region. The first problem is related to the fact that a lidar system is not an "ideal" system and the overlap functions of the $407 \mathrm{~nm}$ and $387 \mathrm{~nm}$ optical channels used for the retrieval of water vapour mixing ratio profile may be different (Whiteman et al., 2001). Lidar water vapour profiles need to be corrected for this effect. Overlap correction is usually determined from comparison with an ensemble of RS92-SGP radiosondes (Whiteman et al., 2006). CIAO water vapour lidar provides measurements starting from 150-300 m a.g.l. after the application of the overlap correction. An assumption about the water content between this altitude and the ground is required to calibrate the lidar profiles using the microwave IPWV. In our case, we assume that in this height range $(0-300 \mathrm{~m})$ the water vapour mixing ratio is linearly distributed between the surface mixing ratio value, measured by a standard meteorological station, and the first available lidar data point. Excluding very strong inversion at the ground, this approximation can be considered enough accurate, since the atmosphere in the 

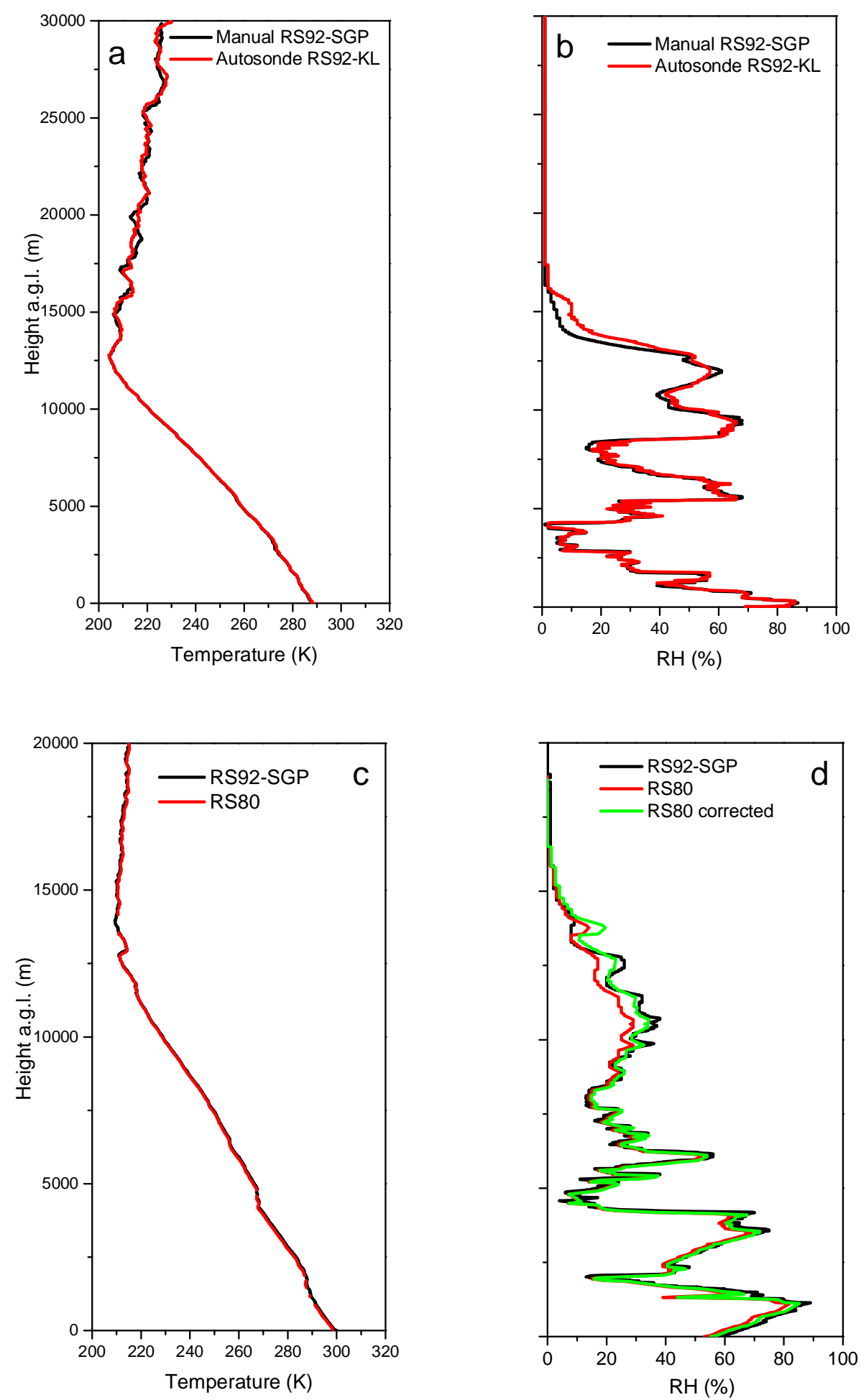

Fig. 2. Examples of dual radiosonde launches performed at CIAO: comparison of the temperature (a) and humidity (b) profiles measured using RS92-SGP and RS92-KL sondes started on 18/10/2004 at 16:13 UT; comparison of temperature (c) and humidity (d) profiles measured using RS80 and RS92-SGP sondes started on 10/08/2004 at 16:49 UT. The plot (d) also includes the RS80 humidity profile corrected according to Leiterer method. Both couples of radiosoundings are co-located and isochronous. 
height range between 0 and $300 \mathrm{~m}$ is well mixed both during night time and daytime conditions (Stull, 1988).

Raman lidar is also able to measure the tropospheric water vapour up to a maximum range depending on the measurement conditions, and on both time and vertical resolutions. This means that, in order to calibrate the lidar profile with the radiometric IPWV, we need an accurate estimation of the water vapour mixing ratio profile above the maximum height available from lidar profiles. The use of a nearest radiosounding, in time and space (co-located or from the radiosounding station of Brindisi Casale), or the use of a climatologic profile from the co-located radiosounding dataset can supply to this request. Depending on the measurement conditions, water vapour Raman lidar profiles are retrieved up to $8-10 \mathrm{~km}$ a.g.l. over a temporal resolution of $10 \mathrm{~min}$.

In Fig. 3, a case study is reported relative to the observations of the water vapour mixing ratio profiles performed with the Raman lidar and the microwave profiler at CIAO during the EAQUATE campaign from 17:50 UT to 23:20 UT on 8 September 2004. In particular, the comparison between the radiometric IPWV and the IPWV retrieved from the Raman lidar profiles calibrated using a co-located radiosouding started at 18:02 UT on 8 September 2004 is reported. The series corresponds to the measurements performed during night time. The good agreement between the two estimations of the IPWV confirms the stability of the CIAO Raman lidar system.

Figure 3 also shows the comparison between the water vapour mixing ratio profiles measured by the co-located radiosouding started at 18:02 UT and the lidar water vapour mixing ratio profiles calibrated using the co-located radiosounding (Sonde cal.) and the radiometric IPWV (MWR cal.), respectively. The discrepancy between the water vapour profiles calibrated according to the two relative calibration methods reveals an absolute difference that is within $4 \%$. Moreover, the uncertainty on the calibration constant using the IPWV is typically within $7 \%$. These values show that the calibration of the Raman lidar profiles using the radiometric IPWV is a good alternative to the radiosounding calibration methods, with the advantage of having a sampling of the atmospheric water content more intensive than with the radiosoundings and, therefore, the opportunity to perform a further intensive monitoring of the stability of the lidar calibration.

\subsection{Raman lidar - microwave radiometer integration}

In order to increase the capability in describing the spatial and temporal variability of the atmospheric parameters, it is fundamental to combine the information provided by different sensors. In the last years, many algorithms have been elaborated to synergize and integrate the measurements provided by different ground-based techniques for the improvement of the profiling of temperature, humidity liquid water and wind (Bianco et al., 2005; Löhnert et al., 2009).
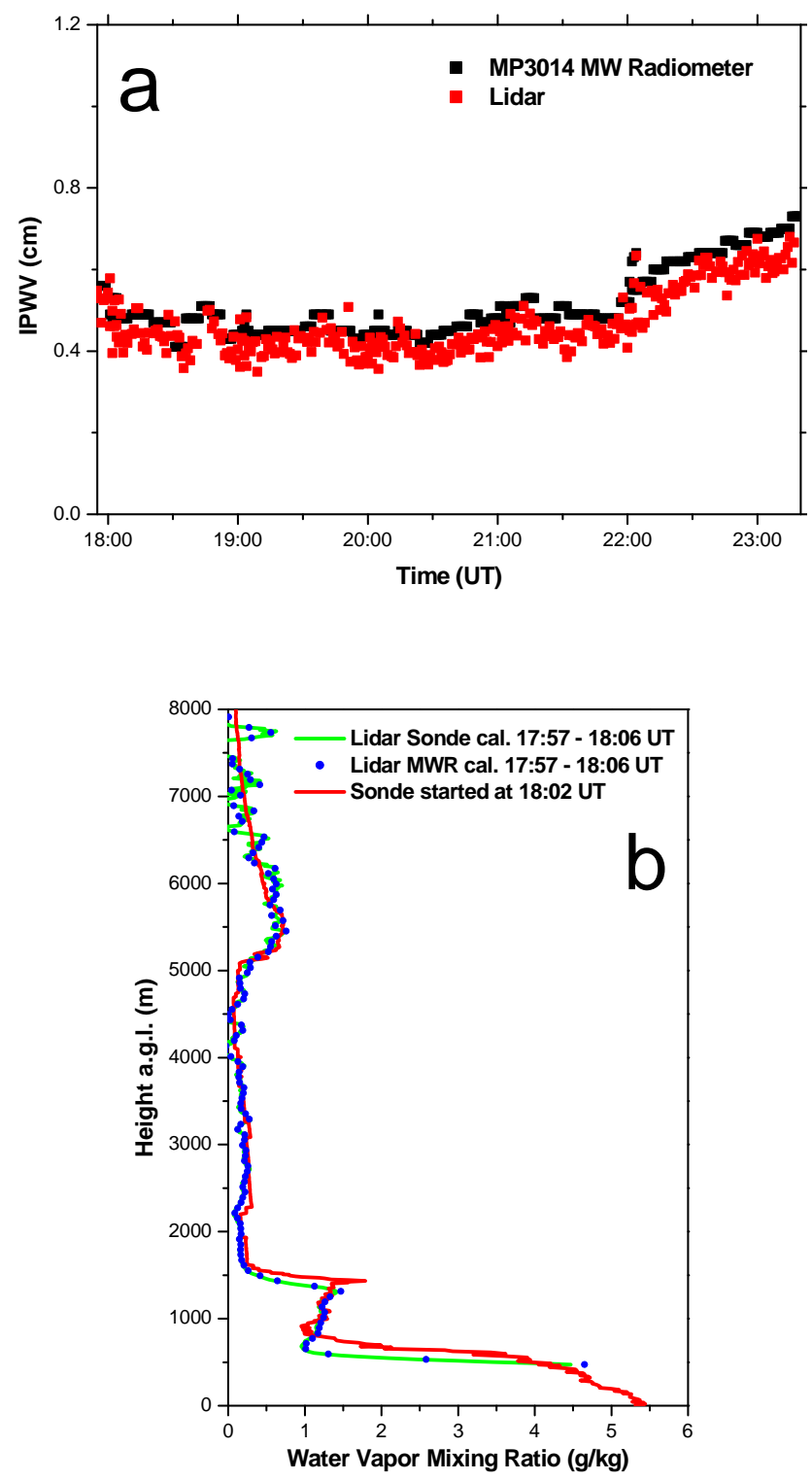

Fig. 3. (a) Comparison of the IPWV retrieved by the MP3014 and obtained from Raman lidar measurements in the period from 17:50 UT to 23:20 UT on 8 September 2004; (b) comparison between the water vapour mixing ratio profiles measured by the radiosonde started at 18:02 UT on 9 September 2004 and the lidar water vapour mixing ratio profiles calibrated using the co-located radiosounding (Sonde cal.) and the radiometric IPWV (MWR cal.), respectively. In the panel (b), the lidar water vapour mixing ratio profiles calibrated using the IPWV is reported using a regular point skipping in order to show the agreement with the profiles calibrated using the co-located radiosounding.

For the study of atmospheric water vapour, Raman lidar and microwave techniques are two of the most powerful approaches and their synergy shows special potentialities. 
Attempts to improve the profiling of the atmospheric water vapour by integrating lidar and passive microwave measurements are already present in the literature (Han and Westwater, 1997). Each of these measurement techniques has strengths and weaknesses. Actually, the Raman lidar technique is able to provide high-resolution water vapour measurements in time and space: this compensates the coarse vertical resolution of the profiles provided with the passive microwave retrievals. On the other hand, microwave profilers are able to operate in nearly all-weather conditions with a high temporal resolution: this compensates the limitation of the Raman lidar measurements performed during daytime or in presence of low clouds. Therefore, the development of suitable retrieval algorithms that integrate lidar and microwave measurements is a right way to improve the profiling of atmospheric water vapour.

Here, we introduce a retrieval scheme for the profiling of water vapour through the integration of Raman lidar and microwave measurements based on the use of the Kalman filter. The main goal of this integration approach is to provide an accurate estimation of the vertical profile of water vapour mixing ratio in the region extending from the ground to $10 \mathrm{~km}$ a.g.l. in presence of thick clouds or during daytime observations.

Kalman filter is a sequential filter method and constitutes an attractive option for the integration of measurements provided by different techniques (Kalman et al., 1960). Kalman filter is based on two groups of equations. At a certain time step i-1, let $\hat{x}_{\mathrm{i}-1}$ the estimation of the state variable (the parameter to retrieve, in our case the vertical profile of water vapour mixing ratio) and let us assume a stochastic propagation model that maps $\hat{x}_{\mathrm{i}-1}$ and $\hat{x}_{\mathrm{i}}$. The first group of equation, so called "time update equations", provides an intermediate background estimation $\boldsymbol{x}_{\mathrm{i}}^{b}$ that is the result of the application of the propagation model to the estimation of the state variable $\hat{x}_{\mathrm{i}-1}$ at the time step i-1. The second group uses $\boldsymbol{x}_{\mathrm{i}}^{b}$ as a first guess to improve, using the observation vector $\boldsymbol{y}_{\mathrm{i}}$. This equation group is called "measurement update" and it performs the effective retrieval of the solution using the observation error covariance matrices to calculate the gain of the filter. The observation vector and the estimate of the state variable are related by the equation:

$\boldsymbol{y}_{\mathrm{i}}=\mathbf{H}_{\mathrm{i}} \hat{x}_{\mathrm{i}}+\boldsymbol{\varepsilon}_{\mathrm{i}}$

where $\mathbf{H}$ is the measurement matrix, $\hat{x}_{\mathrm{i}}$ is a new state estimate that lies in between the background and observation vectors, and has a better estimated uncertainty than either alone, and $\varepsilon$ is the measurement error vector of a process assumed as white Gaussian noise processes with zero-mean. This scheme is repeated every time step and this indicates that the Kalman filter works recursively in time. A complete description of Kalman filtering and of its mathematical formalism is provided in the Appendix A.
In the proposed retrieval scheme, the measurement matrix $\mathbf{H}$ differs from an identity matrix only for the first 12 rows filled in with the microwave weighting functions calculated using Rosenkranz98 (Rosenkranz, 1998) and MPM87 (Liebe and Layton, 1987) radiative transfer models in the $\mathrm{K}$ and $\mathrm{V}$ band, respectively. The observation vector $\boldsymbol{y}=\left[\mathrm{Tb}_{1}, \mathrm{~Tb}_{2}, \ldots \ldots . ., \mathrm{Tb}_{12}, \mathrm{WV}_{1}, \mathrm{WV}_{2}, \ldots ., \mathrm{WV}_{10 \mathrm{~km}}\right]^{T}$ is n-dimensional and consists of the twelve microwave brightness temperatures $\left(\mathrm{Tb}_{\mathrm{i}}\right)$ observed with the MP3014 and by the Raman lidar water vapour mixing ratio profile $\left(\mathrm{WV}_{\mathrm{n}}\right)$ up to $10 \mathrm{~km}$ a.g.l.

The entire lidar profile is used in the integration scheme: this is a disadvantage from a computational point of view, but allows to avoid both further assumptions related to the cloud base definition and to the use of criteria for cutting the lidar profile at a selected height level. In this way only the accuracy of the lidar profile, depending directly on the lidar signal-to-noise ratio, drives the weight of the lidar profile in the retrieval scheme and its contribution to the retrieval of the integrated water vapour guess.

The measurement error vector $\varepsilon$ is constituted by the $\mathrm{Tb}$ errors, determined according to what is proposed in Hewison et al. (2006), and by the lidar mixing ratio errors that include the contribution of the calibration error (Whiteman et al., 2001); the corresponding covariance matrix includes both the autocovariance terms of microwave and Raman lidar observation errors as well as cross covariance terms, calculated at all levels on long time series of simultaneous measurements.

The retrieval algorithm is initialized using an estimation of the vertical profile of water vapour mixing ratio in the whole tropospheric range up to $10 \mathrm{~km}$ a.g.l., typically obtained from the last available lidar profile before cloud occurrence or from a co-located radiosouding. Moreover, the filter is reinitialized as soon as a cloud free lidar profile up to $10 \mathrm{~km}$ a.g.l. or a co-located radiosouding profile is available.

The algorithm can be applied to all non-precipitating conditions; in presence of low clouds (about $1 \mathrm{~km}$ a.g.l.) the algorithm progressively reduces to a passive retrieval. Tests relative to the algorithm performances have shown that the profiles provided by the integration scheme are independent on the initialization profile in less than $1.5 \mathrm{~h}$. The algorithm has been applied to long time series of measurements $(>3 \mathrm{~h})$ selected in the database collected from February 2004 to March 2006, the most interesting cases of which are related to the presence of clouds or to daytime conditions. The performances of the integration approach are dependent on the cloud base height, for cloudy conditions, and on the lidar signal-to-noise ratio, for daytime measurements. A statistical analysis relative to all the investigated case studies shows a root mean square (r.m.s.) deviation between the water vapour mixing ratio profiles obtained from radiosoundings and those retrieved from Kalman algorithm lower than $0.2 \mathrm{~g} \mathrm{~kg}^{-1}\left(0.25 \mathrm{~g} \mathrm{~m}^{-3}\right)$ up to $3 \mathrm{~km}$ a.g.l., where 
the lidar profiles play a major role, lower than $0.6 \mathrm{~g} \mathrm{~kg}^{-1}$ $\left(0.5 \mathrm{~g} \mathrm{~m}^{-3}\right)$ from 3 to $5 \mathrm{~km}$ a.g.l. and lower than $0.25 \mathrm{~g} \mathrm{~kg}^{-1}$ $\left(0.25 \mathrm{~g} \mathrm{~m}^{-3}\right)$ above. These results can be compared with the typical products of the neural network retrieval applied to the microwave Tbs (Ware et al., 2003). The root mean square (r.m.s.) deviation of the radiometer humidity profiles is within $0.8-1.2 \mathrm{~g} \mathrm{~m}^{-3}$ below $3 \mathrm{~km}$ while it decreases with the height and is within $0.4-0.8 \mathrm{~g} \mathrm{~m}^{-3}$ from 3 to $5 \mathrm{~km}$ a.g.l. and is lower than $0.4 \mathrm{~g} \mathrm{~m}^{-3}$ above. The r.m.s. deviation in terms of $\mathrm{g} \mathrm{m}^{-3}$ (reported in brackets) is calculated using an air density profile obtained from co-located radiosounding temperature and pressure measurements.

A case study relative to the integration of lidar and microwave measurements collected from 17:00 UT up to 24:00 UT on 20 February 2004 is reported (Fig. 4) in order to show the algorithm performances. It is characterized by the presence of altostratus clouds, with a low variable cloud base height oscillating around $3.5 \mathrm{~km}$ a.g.l. until 21:15 UT and, subsequently, by the presence of fast falling cirrus clouds up to the end of the series. In this case, the filter has been initialized using a co-located radiosounding started at 15:45 UT on 20 February 2004. The lidar measurements for the selected case study, shown in Fig. 4a, have an effective resolution, as defined in Pappalardo et al. (2004b) ranging, between 60 and $360 \mathrm{~m}$ and a temporal resolution of 10 min: lidar measurements provide a fine description of the water vapour field, penetrating also the observed altostratus clouds above their base, but the extinction due to the clouds does not allow to profile water vapour neither within the cloud nor above.

The integration of the lidar information with the microwave Tbs in the single retrieval scheme is able to provide an estimation of the water vapour mixing ratio profile up to $10 \mathrm{~km}$ above the station and, therefore, to estimate the cloud structure up to its top (Fig. 4b). Though the resolution of these water vapour profiles is coarser than the lidar vertical resolution, the Kalman algorithm provides an operational product that overruns possible limitations in the Raman lidar measurements and provides reliable estimation of the tropospheric water vapour. The comparison with the time series of Fig. 4a shows a slight degradation of the water vapour profile resolution in the PBL with respect to the original lidar measurements. However, this can be compensated performing a final merging between the filter estimation and the original water vapour lidar profile.

The error of the retrieved profile, described in Appendix $\mathrm{A}$, is obtained from the trace of the error covariance matrix, while the profile vertical resolution $\Delta z$ is defined in Eq. (A7) of the Appendix.

In Fig. 4c, the analysis of the Lokall-Modell, designed by the German Weather Service (DWD), is also shown. The model output has an horizontal resolution of $17 \mathrm{~km}$ and a temporal resolution of $1 \mathrm{~h}$. The comparison between the time series obtained from the Kalman integration algorithm and the model shows that the model is able to capture an average behaviour of the water vapour field as well as the increase in the water vapour content that characterizes the end of the time series. However, the model is unable to provide a detailed description of the temporal evolution of the humidity structures, mainly due to its limited vertical resolution. This comparison shows also that a complete model evaluation can be accomplished only if an estimation of tropospheric water vapour is available in the full troposphere. The integration of active and passive profiling technique can fulfil this need. In Fig. $4 \mathrm{~d}$ the comparison among the profile retrieved applying the integration algorithm, the profile obtained from an independent RS80 sonde started at 21:00 UT and the simultaneous profile obtained from the microwave profiler applying a neural network algorithm are shown. The RS80 temperature and $\mathrm{RH}$ profiles are corrected for the dry-bias problem using Leiterer correction. This comparison further shows that the presented integration approach provides an estimation of the water vapour mixing ratio profiles that from one side preserves the high accuracy and resolution of lidar measurement beneath the clouds, and from the other side results in a better agreement with the radiosouding profile both in the cloud region and above with respect to the neural network retrieval. This agreement is influenced by the distance of the radiosouding with respect to the launch station. This can explain the possible differences in the humidity structures in the two different atmospheric regions investigated by the ground based remote sensing station and by the radiosouding, respectively. However, the presence of cirrus clouds observed over Potenza by the lidar well fits the increase of the water vapour content above $6 \mathrm{~km}$. Improvements in the error and in the vertical resolution of the retrieved profiles with respect to the microwave neural retrieval are also obtained.

\section{Summary and outlook}

CIAO represents a well established ground based remote sensing observatory for the study of weather and climate. The observatory consists of a combination of advanced systems able to provide high quality long term observations of aerosol and cloud properties. Since 2000, systematic observations of aerosol, water vapour and clouds have been collected and the acquisition of new active and passive microwave profilers has strengthened the equipment required for performing accurate aerosol and cloud observations. Currently, CIAO represents the largest ground based remote sensing station in the Mediterranean Basin and is one of the main atmospheric observatories in Europe. This potentiality has allowed CIAO to become one of the fifteen backbone stations of GRUAN.

The CIAO database represents an optimal basis to study the synergy between different sensors and to use integration approaches for the long-term monitoring as well as for the study of aerosol-clouds-radiation interactions. 


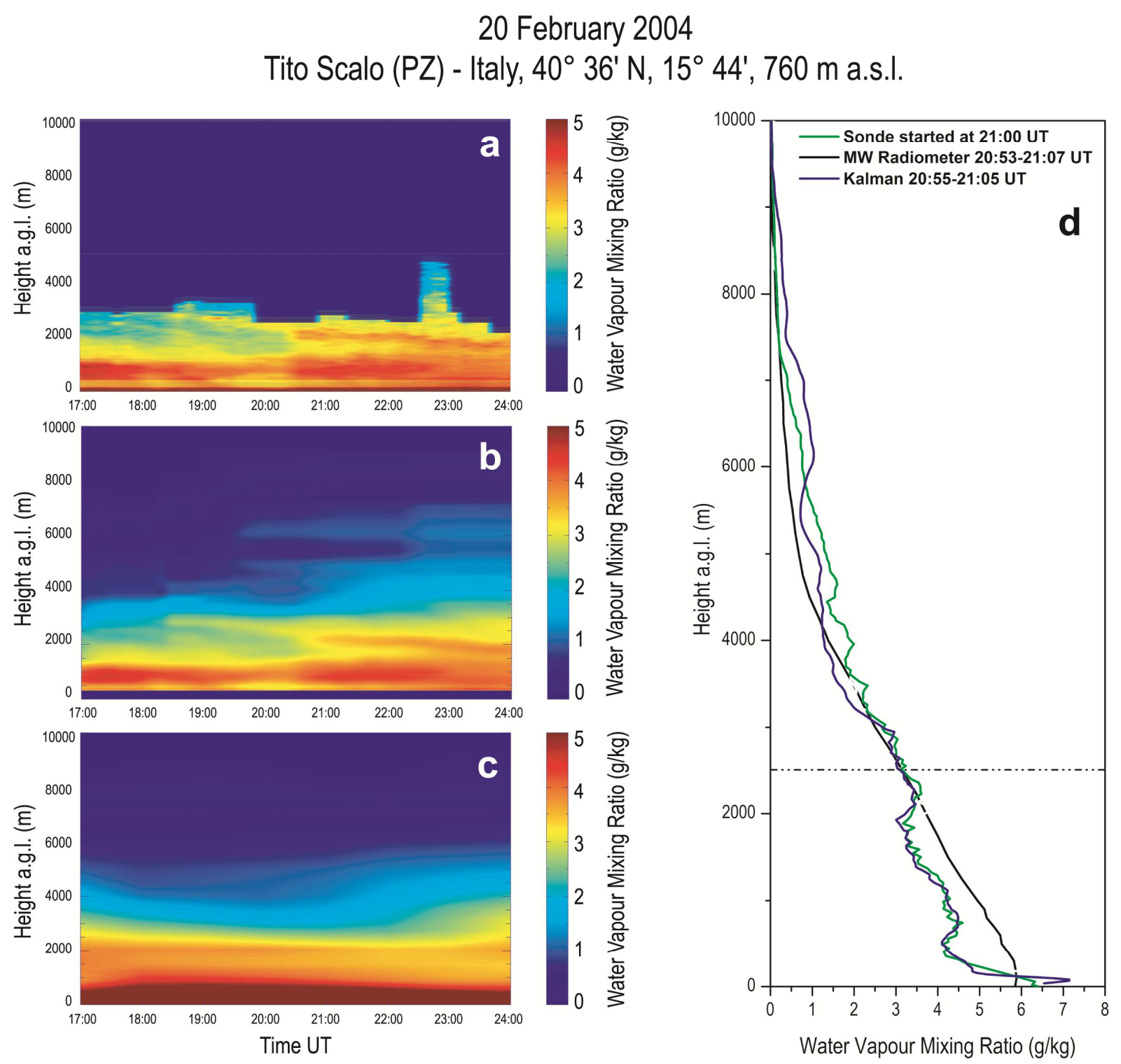

Fig. 4. (a) Time series of the water vapour mixing ratio profile as measured by the water vapour Raman lidar operational at the CNR-IMAA on the 20 February 2004; (b) time series of the water vapour mixing ratio profile obtained using the integration algorithm based on the Kalman filtering; (c) time series of the water vapour mixing ratio profile output by the DWD Lokall-Modell; (d) comparison of the water vapour mixing ratio profile obtained by a co-located radiosouding (Sonde) started at 21:00 UT, the microwave radiometer (MW Radiometer) and using the integration algorithm (Kalman).

In this paper, two examples of the synergies and advanced integration schemes developed at CIAO are reported. In particular, we show an example of the calibration of water vapour Raman lidar profiles obtained using the IPWV retrieved by the microwave profiler as reference measurement. This calibration method shows performances comparable with those obtained using the radiosounding calibration, with a variability of the calibration constant that is lower than $7 \%$ and a difference between the two calibration methods lower than $4 \%$. We also describe a novel integration approach, based on the use of the Kalman filtering, for improv- ing the water vapour profiling in nearly all weather conditions through the integration of Raman lidar and microwave measurements. Though the retrieval provides a description of tropospheric water vapour with a resolution coarser than the lidar, the integration retrieval is able to provide a more operational product that allows us to override possible limitations in the Raman lidar measurements due to the presence of thick clouds or daytime solar background. The reported case study also shows that the proposed integration approach is in a better agreement with the co-located radiosounding profile with respect to the neural network retrieval applied to the 
microwave Tbs only. The discussed examples are representative of the potential of large infrastructures in demonstrating the performance of ground based profiling techniques for the observation of atmospheric key variables.

Other integration approaches for the retrieval of aerosol properties, water vapour and liquid water content are under evaluation. Studies are in progress in particular with the main goal to enhance the knowledge of the aerosol-clouds interactions and the characterization of cloud liquid water content through the integration of lidar, microwave and cloud-radar measurements. Moreover, the availability of MIRA-36 cloud radar gives us also the possibility to provide new parameters and, therefore, to increase the knowledge of the cloud processes as well as to investigate nucleation processes. The integration among co-located multi-wavelength Raman lidar, cloud radar and microwave profiler observations will be one of the main future strategies at CIAO for the study of these interactions.

\section{Appendix A}

Kalman filter is based on two groups of equations. The first group (Eq. A1 and A2), so-called "time update", projects the state variable $x$ (in our case, the water vapour mixing ratio profile) forward in time from the time step i- 1 to the time step i:

$\boldsymbol{x}_{\mathrm{i}}^{b}=\mathbf{A} \hat{x}_{\mathrm{i}-1}+\boldsymbol{w}_{\mathrm{i}-1}$

$\mathbf{P}_{\mathrm{i}}^{b}=\mathbf{A} \mathbf{P}_{\mathrm{i}-1} \mathbf{A}^{T}+\mathbf{Q}_{\mathrm{i}-1}$

In Eq. (A1), $\hat{x}$ indicates the estimation of the state variable and $\mathbf{A}$ is the transition matrix connecting the previous state vector at the time step i-1 to the bakground vector $\boldsymbol{x}_{\mathrm{i}}^{b}$ at the time step i. Here, the transition matrix $\mathbf{A}$ is assumed to be an identity matrix, that means the transition is approximated by propagating the state vector unchanged. The vector $\boldsymbol{w}$ is the transition error calculated using long time series of lidar data according to the approach proposed by Han and Westwater (1997), but averaged on 1 hour integration time to reduce the transition error at the upper levels. $\mathbf{P}$ and $\mathbf{P}^{b}$ indicate error covariance matrices of the state and of the background vectors respectively, here they are the estimation of the water vapour mixing ratio profile and of the profile obtained from Eq. (A1). Finally, $\mathbf{Q}$ is the covariance matrices of $w$, assumed as white Gaussian noise processes with zero-mean.

The second equation group (Eq. A3-A5) is devoted to the correction of the background estimation $\boldsymbol{x}_{\mathrm{i}}^{b}$ (i.e. the forecast) by assimilating the experimental measurement to get an improved a posteriori estimate:

$\hat{x}_{\mathrm{i}}=\boldsymbol{x}_{\mathrm{i}}^{b}+\mathbf{K}_{\mathrm{i}}\left(y_{\mathrm{i}}-\mathbf{H}_{\mathrm{i}} \boldsymbol{x}_{\mathrm{i}}^{b}\right)$
$\mathbf{P}_{\mathrm{i}}=\left(\mathbf{I}-\mathbf{K}_{\mathrm{i}} \mathbf{H}_{\mathrm{i}}\right) \mathbf{P}_{\mathrm{i}}^{\mathrm{b}}$

$\mathbf{K}_{\mathrm{i}}=\mathbf{P}_{\mathrm{i}}^{\mathrm{b}} \mathbf{H}_{\mathrm{i}}^{T}\left[\mathbf{H}_{\mathrm{i}} \mathbf{P}_{\mathrm{i}}^{\mathrm{b}} \mathbf{H}_{\mathrm{i}}^{T}+\mathbf{R}_{\mathrm{i}}\right]^{-1}$

$\mathbf{H}$ is the measurement matrix that correlates the state and the observation vector (i.e. the final estimate and the measurement, respectively) at the time step i:

$\boldsymbol{y}_{\mathrm{i}}=\mathbf{H}_{\mathrm{i}} \hat{x}_{\mathrm{i}}+\boldsymbol{\varepsilon}_{\mathrm{i}}$

In Eq. (A6), $\boldsymbol{\varepsilon}$ is the measurement error vector and $\mathbf{R}$ is the corresponding error covariance matrix, assumed as white Gaussian noise processes with zero-mean. In the update Eqs. (A3), (A4), (A5), $\mathrm{K}$ is the gain of the Kalman filter.

Finally, the estimate error of the state vector is obtained from the trace of $\mathbf{P}_{\mathrm{i}}$, while the profile vertical resolution $\Delta z$ of the state vector is defined according to Rodgers (2000) as the reciprocal of the diagonal of the averaging kernel matrix defined as:

$\Delta z=\delta z / \operatorname{diag}\left(\mathbf{H}_{\mathrm{i}} \mathbf{K}_{\mathrm{i}}\right)$

where $\delta z$ is the level spacing of the output profile and $\operatorname{diag}\left(\mathbf{H}_{\mathrm{i}}\right.$ $\mathbf{K}_{\mathbf{i}}$ ) are the diagonal elements of the matrix $\mathbf{K}_{\mathrm{i}} \mathbf{H}_{\mathrm{i}}$.

Acknowledgements. The authors acknowledge the ESA financial support under the ESTEC contract 21487/08/NL/HE, and the ESRIN contracts 21769/08/I-OL and 22202/09/I-EC. The financial support for EARLINET by the European Commission under grant RICA 025991 is gratefully acknowledged. The authors acknowledge the support of the European Commission through GEOmon Integrated Project under the 6th Framework Programme (contract FP6 FP6 - 2005 - Global - 4 - 036677). The authors also acknowledge the financial support of the Department of the Italian Civil Protection (DPC) under the contract "Intesa Operativa n. 624 di rep., 21 December 2006. Finally, The authors acknowledge the Cloudnet project (European Union contract EVK2-2000-00611) for providing the water vapour mixing ratio profiles on the DWD Lokal-Modell grid data, which was produced by the University of Reading and the Deutscher Wetterdienst (DWD).

Edited by: A. Apituley

\section{References}

Ackermann, I. J., Hass, H., Memmesheimer, M., Ebel, A., Binkowski, F. S., and Shankar, U.: Modal aerosol dynamics model for Europe: Development and first applications, Atmos. Environ., 32(17), 2981-2999, 1998.

Ansmann, A., Riebesell, M., and Weitkamp, C.: Measurement of atmospheric aerosol extinction profiles with a Raman lidar, Opt. Lett., 15, 746-748, 1990.

Behrendt, A. and Nakamura T.: Calculation of the calibration constant of polarization lidar and its dependency on atmospheric temperature, Opt. Exp., 10(16), 805-817, 2002.

Bianco, L., Cimini, D., Marzano, F., and Ware, R.: Combining Microwave Radiometer and Wind Profiler Radar Measurements for High-Resolution Atmospheric Humidity Profiling, J. Atmos. Oceanic Technol., 22, 949-965, 2005. 
Bösenberg, J., Ansmann, A., Baldasano, J. M., Balis, D., Böckmann, Ch., Calpini, B., Chaikovsky, A., Flamant, P., Hagard, A., Mitev, V., Papayannis, A., Pelon, J., Resendes, D., Schneider, J., Spinelli, N., Trickl, Th., Vaughan, G., Visconti, G., and Wiegner, M.: EARLINET: A European Aerosol Research Lidar Network, in: Advances in Laser Remote Sensing, edited by: Dabas, A., Loth, C., and Pelon, J., ISBN 2-7302-0798-8, 155-158, 2001

Cadeddu, M. P., Turner, D. D., and Liljegren, J. C.: A neural network for real-time retrievals of PWV and LWP from Arctic millimeter-wave ground-based observations, IEEE Trans. Geosci. Remote Sens., 47, 1887-1900, 2009.

Chiu, J. C., Huang, C.-H., Marshak, A., Slutsker, I., Giles, D. M., Holben, B. N., Knyazikhin, Y., and Wiscombe, W. J.: Cloud optical depth retrievals from the Aerosol Robotic Network (AERONET) cloud mode observations, J. Geophys. Res., 115, D14202, doi:10.1029/2009JD013121, 2010.

Cornacchia, C., Amodeo, A., Mona, L., Pandolfi, M., Pappalardo, G., and Cuomo, V.: The IMAA Raman lidar system for water vapour measurements, Reviewed and revised papers presented at the 22nd International Laser Radar Conference (ILRC22), Matera, Italy, ESA SP-561, 107-110, 2004.

Di Girolamo, P., Gagliardi, R. V., Pappalardo, G., Spinelli, N., Velotta, R., and Berardi, V.: Two wavelength lidar analysis of stratospheric aerosol size distribution, J. Aerosol Sci., 26, 9891001, 1995

Freudenthaler, V., Esselborn, M., Wiegner, M., Heese, B., Tesche, M., Ansmann, A., Mueller, D., Althausen, D., Wirth, M., Fix, A., Ehret, G., Knippertz, P., Toledano, C., Gasteiger, J., Garhammer, M., and Seefeldner, M.: Depolarization ratio profiling at several wavelengths in pure Saharan dust during SAMUM 2006. Tellus B, 61, 165-179, 2009.

Freudenthaler, V., Gross, S., Engelmann, R., Mattis, I., Wandinger, U., Pappalardo, G., Amodeo, A., Giunta, A., D’Amico, G., Chaikovsky, A., Osipenko, F., Slesar, A., Nicolae, D., Belegante, L., Talianu, C., Serikov, I., Linne, H., Jansen, F., Wilson, K., de Graaf, M., Apituley, A., Trickl, T., Giehl, H., and Adam, M.: EARLI09 - Direct intercomparison of eleven EARLINET lidar, 25th International Lidar Radar Conference, 5/7/2010-9/7/2010, St. Petersburg, ILRC 25, 891-894, 2010.

GCOS-107 report, Systematic Observation Requirements for Satellite-based Products for Climate - Supplemental details to the satellite-based component of the Implementation Plan for the Global Observing System for Climate in Support of the UNFCCC, September, 2006.

Han, Y. and Westwater, E. R.: Applications of Kalman Filtering to Derive Water Vapor from Raman Lidar and Microwave Radiometers, J. Atmos. Oceanic Technol., 14(1), 481-48, 1997.

Hewison, T., Cimini, D., Martin, L., Gaffard, C., and Nash, J.: Validating atmospheric absorption models in clear air using groundbased microwave radiometers, Meteorol. Z., 15, 27-36, 2006.

Holben, B. N., Tanre, D., Smirnov, A., Eck, T. F., Slutsker, I., Abuhassan, N., Newcomb, W. W., Schafer, J., Chatenet, B., Lavenue, F., Kaufman, Y. J., Vande Castle, J., Setzer, A., Markham, B., Clark, D., Frouin, R., Halthore, R., Karnieli, A., O’Neill, N. T., Pietras, C., Pinker, R. T., Voss, K., and Zibordi, G.: An emerging ground-based aerosol climatology: Aerosol Optical Depth from AERONET, J. Geophys. Res., 106, 12067-12097, 2001.

Kalman, R. E.: A new approach to linear filtering and prediction problems, J. Basic Eng-T. ASME, 82, 35-45, 1960.

Illingworth, A. J., Hogan, R. J., O'Connor, E. J., Bouniol, D., Brooks, M. E., Delanoe, J., Donovan, D. P., Gaussiat, N., Goddard, J. W. F., Haeffelin, M., Klein Baltink, H., Krasnov, O. A., Pelon, J., Piriou, J. M., and van Zadelhoff, G. J.: Cloudnet - continuous evaluation of cloud profiles in seven operational models using ground-based observations, Bull. Amer. Meteor. Soc., 88(6), 883-898, 2007.

Immler, F. J., Dykema, J., Gardiner, T., Whiteman, D. N., Thorne, P. W., and Vömel, H.: Reference Quality Upper-Air Measurements: guidance for developing GRUAN data products, Atmos. Meas. Tech., 3, 1217-1231, doi:10.5194/amt-3-1217-2010, 2010.

Intergovernmental Panel on Climate Change (IPCC), Climate Change 2007: The Scientific Basis, IPCC final report, 2007.

Leiterer, U., Dier, H., and Naebert, T.: Improvements in radiosonde humidity profiles using RS80/RS90 radiosondes of Vaïsala, Contrib. Atmos. Phys., 70, 319-336, 1997.

Liebe, H. J and Layton, D. H.: Millimetre-Wave Properties Of The Atmosphere: Laboratory Studies And Propagation Modeling, NTIA-Report 87-224, Natl. Telecommun, And Inf. Admin, Boulder, CO, 1987.

Lilly, D. K., Waco, D., and Aldefang, S.: Stratospheric mixing estimated from high altitude turbulence measurements, J. Appl. Meteorol., 13, 488-493, 1974.

Löhnert, U., Turner, D., and Crewell, S.: Ground-Based Temperature and Humidity Profiling Using Spectral Infrared and Microwave Observations. Part I: Simulated Retrieval Performance in Clear-Sky Conditions, J. Appl. Meteorol. Clim., 48, 10171032, 2009.

Madonna, F., Gueldner, J., D’Amico, G., Engelbart, D. A. M., and Pappalardo, G.: Intercomparison of two microwave profilers during launch-2005, $7^{\text {th }}$ International Symposium on Tropospheric Profiling (ISTP), Boulder, CO, 11-17 giugno 2006, 2006.

Matthias V., Balis, D., Bösenberg, J., Eixmann, R., Iarlori, M., Komguem, L., Mattis, I., Papayannis, A., Pappalardo, G., Perrone, M. R., and Wang, X.: Vertical aerosol distribution over Europe: Statistical analysis of Raman lidar data from 10 European Aerosol Research Lidar Network (EARLINET) stations, J. Geophys. Res.-Atmos., 109(D18), D18201, doi:10.1029/2004JD004638, 2004.

Mona, L., Amodeo, A., Pandolfi, M., and Pappalardo, G.: Saharan dust intrusions in the Mediterranean area: three years of Raman lidar measurements, J. Geophys. Res., 111, D16203, doi:10.1029/2005JD006569, 2006.

Mona, L., Cornacchia, C., D’Amico, G., Di Girolamo, P., Pappalardo, G., Pisani, G., Summa, D., Wang, X., and Cuomo, V.: Characterization of the variability of the humidity and cloud fields as observed from a cluster of ground-based lidar systems, Q. J. Roy. Meteorol. Soc., 133(S3) 257-271, 2007.

Mona, L., Pappalardo, G., Amodeo, A., D’Amico, G., Madonna, F., Boselli, A., Giunta, A., Russo, F., and Cuomo, V.: One year of CNR-IMAA multi-wavelength Raman lidar measurements in coincidence with CALIPSO overpasses: Level 1 products comparison, Atmos. Chem. Phys., 9, 7213-7228, doi:10.5194/acp-97213-2009, 2009.

Müller, D., Wandinger, U., Althausen, D., and Fiebig, M.: Comprehensive particle characterization from three-wavelength Ramanlidar observations: case study, Appl. Opt., 40(27), 4863-4869, 
2001.

Müller, D., Tesch, M.e, Eichler, H., Engelmann, R., Althausen, D., Ansmann, A., Cheng, Y. F., Zheng, Y. H., and Hu, M.: Strong particle light absorption over the Pearl River Delta (South China) and Beijing (North China) determined from combined Raman lidar and Sun photometer observations, Geophys. Res. Lett., 33, L20811, doi:10.1029/2006GL027196, 2006.

Pappalardo, G., Amodeo, A., Mona, L., Pandolfi, M., Pergola, N., and Cuomo, V.: Raman lidar observations of aerosol emitted during the 2002 Etna eruption, Geophys. Res. Lett., 31, L05120, doi:10.1029/2003GL019073, 2004a.

Pappalardo G., Amodeo, A., Pandolfi, M., Wandinger, U., Ansmann, A., Bosenberg, J., Matthias, V., Amiridis, V., de Tomasi, F., Frioud, M., Iarlori, M., Komguem, L., Papayannis, A., Rocadenbosch, F., and Wang, X.: Aerosol lidar intercomparison in the framework of EARLINET, Part III. Raman lidar algorithm for aerosol extinction, backscatter and lidar ratio, Appl. Opt., 43(28), 5370-5385, 2004b.

Pappalardo, G., Wandinger, U., Mona, L., Hiebsch, A., Mattis, I., Amodeo, A., Ansmann, A., Seifert, P., Linné, H., Apituley, A., Alados Arboledas, L., Balis, D., Chaikovsky, A., D’Amico, G., De Tomasi, F., Freudenthaler, V., Giannakaki, E., Giunta, A., Grigorov, I., Iarlori, M., Madonna, F., Mamouri, R.-E., Nasti, L., Papayannis, A., Pietruczuk, A., Pujadas, M., Rizi, V., Rocadenbosch, F., Russo, F., Schnell, F., Spinelli, N., Wang, X., and Wiegner, M.: EARLINET correlative measurements for CALIPSO: First intercomparison results, J. Geophys. Res., 115, D00H19, doi:10.1029/2009JD012147, 2010.

Rodgers, C. D.: Inverse Methods for Atmospheric Sounding: Theory and Practice, World Scientific Publishing Co. Ltd., 2000.

Rosenkranz, P. W.: Water vapor microwave continuum absorption: a comparison of measurements and models, Rad. Sci., 33, 919928, 1998.

Russchenberg, H. W. J., Bosveld, F., Swart, D., ten Brink, H., de Leeuw, G., Uijlenhoet, R., Arbesser-Rastburg, B., van der Marel, H., Ligthart, L., Boers, R., and Apituley, A.: Ground-based atmospheric remote sensing in The Netherlands; European outlook, IEICE Transactions on Communications, e88-b(6), June 2005.

Sherlock V. J., Hauchecorne, A., and Lenoble, J.: Methodology for the independent calibration of Raman backscatter water-vapor lidar systems, Appl. Opt., 38, 5816-5837, 1999.

Solheim, F., Godwin, J., Westwater, E., Han, Y., Keihm, S., Marsh, K., and Ware, R.: Radiometric profiling of temperature, water vapor, and cloud liquid water using various inversion methods, Radio Sci., 33, 393-404, 1998.
Stokes, G. M. and Schwartz, S. E.: The Atmospheric and Radiation Measurement (ARM) Project: Programatic background and design of the cloud and atmospheric radiation tested, Bull. Amer. Meteor. Soc., 75, 1201-1221, 1994.

Stull, R. B.: An Introduction to Boundary Layer Meteorology, Kluwer Academic, 666 pp., 1988.

Taylor, J. P., Smith, W., Cuomo, V., Larar, A., Zhou, D., Serio, C., Maestri, T., Rizzi, R., Newman, S., Antonelli, P., Mango, S., Di Girolamo, P., Esposito, F., Grieco, G., Summa, D., Restieri, R., Masiello, G., Romano, F., Pappalardo, G., Pavese, G., Mona, L., Amodeo, A., and Pisani G.: EAQUATE - An International Experiment For Hyper-spectral Atmospheric Sounding Validation, BAMS, 203-218, February 2008.

Turner, D. D., Lesht, B. M., Clough, S. A., Liljegren, J. C., Revercomb, H. E., and Tobin, D. C.: Dry bias and variability in Vaisala radiosondes: The ARM experience, J. Atmos. Oceanic Technol., 20, 117-132, 2003.

Wandinger, U. and Ansmann, A.: Experimental determination of the lidar overlap profile with Raman lidar, Appl. Opt., 41(3), 511-514, 2002.

Ware, R., Carpenter, R., Güldner, J., Liljegren, J., Nehrkorn, T., Solheim, F., and Vandenberghe, F.: A multichannel radiometric profiler of temperature, humidity, and cloud liquid, Radio Sci., 38(4), 8079, doi:10.1029/2002RS002856, 2003.

Whiteman, D. N., Schwemmer, G., Berkoff, T., Plotkin, H., RamosIzquierdo, L., and Pappalardo, G.: Performance modelling of an airborne Raman water vapour lidar, Appl. Opt., 40(3), 375-390, doi:10.1364/AO.40.000375, 2001.

Whiteman, D. N.: Examination of the traditional Raman lidar technique. I. Evaluating the temperature-dependent lidar equations, Appl. Opt. 42(15), 2571-2591, 2003a.

Whiteman D. N.: Examination of the traditional Raman lidar technique. II. Evaluating the ratios for water vapor and aerosols, Appl. Opt. 42(15), 2593-2608, 2003b.

Whiteman, D. N., Demoz, B., Rush, K., Schwemmer, G., Gentry, B., Di Girolamo, P., Comer, J., Veselovskii, I., Evans, K., Melfi, S. H., Wang, Z., Cadirola, M., Mielke, B., Venable, D., and Van Hove, T.: Raman water vapor lidar measurements during the international $\mathrm{H} 2 \mathrm{O}$ project. I. Instrumentation and analysis techniques, J. Atmos. Oceanic Technol., 23, 157-169, 2006.

WMO bulletin, 54(4), 185, October 2005.

WMO report, Plan for the implementation of the GAW Aerosol Lidar Observation Network GALION (Hamburg, Germany, 2729 March 2007), TD No. 1443, 52 pp., available at: http: //www.wmo.int/pages/prog/arep/gaw/gaw-reports.html, November 2008 . 